\title{
Experiencia y huella: los cuentos de Óscar Collazos ${ }^{12}$ Experience and mark: short stories of Oscar Collazos
}

\author{
Alejandro José López Cáceres* \\ Recibido: 30 de julio 2011. Aprobado: 20 de Agosto de 2011
}

\begin{abstract}
Resumen
Este articulo presenta al escritor Óscar Collazos y a su obra cuentistica, constituida por cinco obras, desde una ubicación biográfica y bibliográfica. Para ello se detiene en cada uno de sus libros de cuentos y resalta las características memorables que construyen la propuesta estética del cuentista. El autor sitúa a Óscar Collazos como un escritor atento al pulso de su tiempo, que explora la experimentación, el compromiso político y la cultura de masas en sus narraciones, testimoniando su trasegar geográfico y literario.
\end{abstract}

Palabras clave: Óscar Collazos; Cuento colombiano; Cuento Latinoamericano.

\begin{abstract}
This paper presents the writer Oscar Collazos and his short story work, consisting of five works from a biographical and bibliographical location. This stops at every one of his books of short stories and features memorable highlights the aesthetic building storyteller. The author puts Oscar Collazos writer as attentive to the pulse of his time exploring experimentation, political commitment and mass culture in his narrative, witnessing its geographical and literary decant.
\end{abstract}

Keywords: Óscar Collazos; Colombian short story; Latin American short story.

Aunque a todos nos ocurre, muy pocos tienen consciencia plena de ello. La vida nos propicia una multitud de experiencias, nuestra existencia transcurre en escenarios diversos, el mundo se nos aparece repleto de objetos y de eventos. Todo esto deja rastros profundos en nosotros. Sin embargo, la posibilidad de expresar estéticamente dichas huellas exige una sensibilidad especial. En el caso de los escritores, abundan aquellos que saben referir una anécdota de manera divertida — gracias a esta habilidad, sus libros

\footnotetext{
${ }^{12}$ Artículo derivado del proyecto de investigación Biblioteca Afrocolombiana, patrocinado por el Ministerio de Cultura de Colombia, del cual el autor hizo parte en la preparación, organización y estudio de los cuentos del escritor Óscar Collazos.

*Escritor y realizador audiovisual colombiano (Tuluá, 1969). Ha publicado un libro de crónicas: "Tierra posible" (1999), otro de ensayos: "Entre la pluma y la pantalla" (2003), uno de cuentos "Dalí violeta" (2005), y uno más de entrevistas y crónicas: "Al pie de la letra" (2007). Entre el 2004 y el 2008 dirigió la Escuela de Estudios Literarios perteneciente a la Universidad del Valle. Actualmente reside en España y cursa estudios doctorales en la Universidad Complutense de Madrid.
} 
suelen venderse a granel—; pero el arte del relato no se agota allí. La entretención, por el contrario, es un mecanismo que está al servicio de algo mucho más entrañable. Porque, esencialmente, la narración es una forma de conocimiento. Por fortuna, incluso en estos tiempos — tan proclives a la banalización— perviven autores que mantienen su arraigo respecto de la tradición literaria. Contar es el modo privilegiado que siempre hemos tenido para comunicarnos el resultado de las experiencias vitales. Hoy nos repiten hasta el cansancio que un libro es más importante cuanto más se venda, pero los alcances artísticos no se dejan medir toscamente: una obra se torna valiosa en la medida en que nos permite ensanchar nuestra comprensión de la vida. Esto no significa que haya de tener una moraleja o algún tipo de enseñanza explícita; al contrario, un relato capaz de penetrar en las complejidades de la condición humana se resiste a cualquier tipo de simplificación.

Cuando uno se asoma a la obra cuentística de Óscar Collazos (Bahía Solano, Colombia, 1942), se pregunta de dónde proviene la tremenda fuerza que emanan sus relatos. Y, si leemos despacio, muy pronto hallamos respuesta: de la experiencia; es decir, de la vivencia o del testimonio. Sus ficciones están compuestas a partir de lo sabido, por eso respiran sinceridad; sus historias están contadas desde adentro, por eso transmiten conocimiento. A lo largo de su extendida carrera literaria, Óscar Collazos ha escrito cinco libros de cuentos. ${ }^{13}$ Ahora bien, las narraciones pertenecientes a estas colecciones han sido reeditadas en diversos momentos y países, especialmente aquellas que conformaron los dos primeros volúmenes. Resulta importante destacar al menos tres de estas

\footnotetext{
${ }^{13}$ Collazos, Óscar. El verano también moja las espaldas. Editorial Papel Sobrante. Medellín, 1966. . Son de máquina. Editorial Testimonio. Bogotá, 1967. Biografía del desarraigo. Editorial Siglo XXI. Buenos Aires, 1974. . A golpes. Editorial Lumen. Barcelona, 1974. Adiós Europa, adiós. Seix-Barral. Bogotá, 2000.
} 
publicaciones. La primera tuvo lugar en Cuba y fue realizada por Casa de las Américas, en su colección La Honda, en 1970. Dicha selección fue repetida el mismo año por la editorial Arca, de Montevideo, pero con la incorporación de un cuento inédito: Esta mañana del mundo — a solicitud de Marta Traba, el volumen adoptó precisamente este título_- Dos décadas más tarde, en 1993, la Universidad del Valle publicó en Colombia una edición titulada "Primeros cuentos (1964 - 1968)".

Detengámonos un momento más en los relatos que integran las dos colecciones iniciales. El libro de 1966 fue escrito por Collazos durante su periplo entre Buenaventura y Cali, cuando su vocación de escritor sorteaba aún todo tipo de escollos. De hecho, debió trabajar en máquinas de escribir que le prestaban; al principio, en la oficina de su padre, quien gerenciaba en el puerto una empresa de autobuses. Ya en Cali fue Enrique Buenaventura quien le facilitó las del TEC y lo vinculó como asesor de dramaturgia, en 1964. Por aquel entonces, Manuel Mejía Vallejo auspició en Medellín una aventura llamada Editorial Papel Sobrante. Allí fue acogido El verano también moja las espaldas, el debut de Collazos como narrador. Las cosas cambiaron para él a partir de entonces. Por una parte, el maestro antioqueño le regaló una portátil Lettera 22 Olivetti; por otra, este libro le dio al joven autor inmediata notoriedad nacional. ${ }^{14}$ Gracias a ello le sucedió algo inesperado: David Consuegra —el legendario pionero del diseño gráfico en Colombia— le solicitó nuevos cuentos inéditos y le pagó 200 dólares por ellos. Así fue como al año siguiente, en 1967, se publicó “Son de máquina”. Un mes después emprendería Óscar Collazos su primer viaje a Europa.

\footnotetext{
${ }^{14}$ Así consta en la apostilla que Marta Traba redactaría cuatro años más tarde, para la contratapa de la edición uruguaya mencionada atrás: "El libro sorprendió a los expertos y recibió el espaldarazo de los dos mejores escritores contemporáneos, Gabriel García Márquez y Álvaro Cepeda Samudio. Óscar Collazos, chocoano (o sea, proveniente de las más pobres, abandonadas y selváticas provincias de Colombia), silencioso, torpe, insurrecto, se volvió la nueva figura de la literatura nacional”. Cfr. Collazos, Óscar. Esta mañana del mundo. Arca. Montevideo, 1970.
} 
Una lectura hecha al cabo de los años nos permitiría afirmar que, a la postre, estos dos volúmenes son uno solo. Me explico: los personajes que abordan y los dramas que indagan pertenecen al mismo universo; de igual modo, las elaboraciones en su lenguaje y en su narrativa corresponden a un horizonte análogo de exploración. Procuremos adentrarnos un poco más en esta apreciación. Y empecemos señalando un par de rasgos característicos, generales, de dichos relatos: su filiación realista y sus entornos urbanos. El primero lo corrobora el crítico Óscar López cuando afirma que "Collazos no se sale del marco realista desde el que examina con voluntad crítica los escenarios y los individuos, y su papel activo o pasivo en la permanencia de un caos del que no se avizoran salidas promisorias". ${ }^{15}$ Sería importante precisar, eso sí, que no estamos refiriéndonos a un realismo como el que se estilaba en los cánones tradicionales del cuento colombiano, de corte costumbrista. Collazos se ha interesado aquí en explorar ciertos ámbitos vitales — sensaciones, sueños, pensamientos - procurando acercarse a sus propias dinámicas de proyección, a aquella sintaxis anómala; por eso incorpora recursos novedosos, técnicas de la narrativa contemporánea, como el fluir de la consciencia. Podemos hallar entreverados, en algunos de estos relatos, fragmentos muy cercanos al monólogo interior. Así sucede en el cuento titulado Nuevas para la familia, en el cual se narran los aspavientos generados por un hecho frívolo en una familia del puerto: tras ser elegida reina de la universidad, una de las hijas ha salido fotografiada en el periódico más importante del país. Los deliquios de la madre son narrados en primera persona, caóticamente, con lo cual se resalta la estulticia que rige toda aquella situación. Este mismo recurso aparece en El lento olvido de tus sueños, sólo que esta vez se

\footnotetext{
15 López, Óscar. "Óscar Collazos: del compromiso político al disenso, su narrativa”. En: XXVIII International Congress of the Latin American Studies Association. Actas electrónicas. Río de Janeiro, junio de 2009. Pág. 7.
} 
encuentra al servicio de subrayar la angustia que le genera a un blanquito de doce años su inserción en una ciudad repleta de negros y, de otro lado, la tiranía patriarcal, hecha de prohibiciones absurdas y castigos brutales.

En lo que toca a los escenarios de estos cuentos iniciales, nos encontramos todavía en ciudades pequeñas de la costa pacífica colombiana: Bahía Solano y Buenaventura. Allí subsisten vínculos con los imaginarios parroquiales; pero, al mismo tiempo, se vislumbran ya conflictos propios de la modernidad. Refiriéndose a sus primeras narraciones, Luz Mery Giraldo ha anotado que, “en Collazos, los espacios y situaciones urbanas se tejen en dimensiones humanas y existenciales contemporáneas; como Ruiz [Darío], Collazos penetra en las nuevas modalidades del pensamiento, sentimiento y acción de la vida actual". ${ }^{16}$ De esta suerte, podemos toparnos con historias como la que se nos cuenta en Son de máquina - título que rememora aquella guaracha que se hiciera famosa en la voz de Rolando Laserie-. En ella Ernesto, el joven inmigrante que se ha desplazado a Nueva York, epicentro del sueño americano, está de regreso al puerto de Buenaventura. Pero el entorno que halla no se corresponde con la ciudad de sus recuerdos y sus amigos, ni es lugar propicio para sus ambiciones actuales; así que la vida está jugándole una mala pasada, pues ya ha empezado a añorar la ciudad del otro lado, la discoteca Paladium y el esplendor de su rumba. Ni aquí ni allá: tendrá que viajar nuevamente $\mathrm{y}$, en lo sucesivo, la nostalgia se le impondrá como destino. También encontramos en estos dos libros inaugurales, decíamos, relatos que dan cuenta de mentalidades más aldeanas, características de urbes pequeñas, en formación; entonces vemos aparecer esa religiosidad fanática, por ejemplo, propia de horizontes espirituales

\footnotetext{
${ }^{16}$ Giraldo, Luz Mery (selección y prólogo). Nuevo Cuento Colombiano 1975 - 1995. Fondo de Cultura Económica. México, 1997. Pág. 12. 
intransigentes y retardatarios. Tal vez el cuento que mejor ilustra lo dicho es El eclipse, donde el Padre Maldonado ha profetizado, en tono a la vez supersticioso y apocalíptico, un fenómeno natural que habrá de acabar con el pecaminoso puerto. Y es que, en general, las figuras de autoridad que operan en este universo — donde los personajes transitan de una historia a otra - se manifiestan de modo enfermizo. Otra muestra de ello se nos presenta en el drama que vive Alberto, el chico de once años que protagoniza Las causas perdidas. Su madre lo mandó a confesarse y el Padre Gómez lo ha atendido en el solitario silencio de la iglesia. Pero su hermano mayor, quien narra lo sucedido, se percata de que el muchacho ha vuelto a casa demasiado pronto, presa de un mutismo particularmente significativo.

Buena parte del anecdotario que se desarrolla en estas ficciones gravita en torno a contextos familiares, vistos desde perspectivas adolescentes. De allí la recurrencia de temas como la iniciación sexual, la inserción al grupo, la rebeldía frente a la autoridad patriarcal; todo lo cual nos pone sobre una cuestión de particular interés cuando nos aproximamos a esta escritura: sus influencias. Collazos no oculta, asume; no alardea, afirma; no especula, revela. Si bien su carrera se inició en pleno auge del llamado "Boom" latinoamericano —asunto sobre el cual haré un par de anotaciones más adelante-, sus primeros cuentos están marcados por una presencia muy particular, como el mismo autor se lo dijo recientemente en una entrevista al periodista Carlos Ernesto García:

Para mí fue una gran revelación haber leído a los dieciocho años a Jerome D. Salinger, y en especial su libro El guardián en el centeno (...) me di cuenta que hablar desde la autobiografía de un adolescente, o desde la niñez, era perfectamente lícito. Y éste pertenecía a un mundo que no era el mundo rural y mítico de Faulkner, ni siquiera el de García Márquez. Mi infancia y adolescencia transcurrieron en un puerto. Los puertos, por pequeños que sean, son el mayor de los símbolos del cosmopolitismo. Entonces, con Salinger descubrí

Poligramas 36, segundo semestre 2011, ISSN 0120-4130. 
que era posible hablar de la adolescencia y del disgusto y del encabronamiento que todo adolescente tiene sobre las estructuras familiares inmediatas: sobre el principio de autoridad, sobre la moral, sobre el sexo. Así, fue como una apertura y una legitimación de aquello que yo quería hacer. ${ }^{17}$

Desde luego, aquellos relatos de Collazos dialogan con muchos otros autores, lo cual se evidencia, sobre todo, al observar sus técnicas narrativas. En este orden de ideas, se destaca su clara disposición para acoger las particularidades del lenguaje oral y sus registros más populares, de suerte que se vuelve notoria en su escritura una actitud abierta a la experimentación. Esto nos pone sobre la pista del "Boom" y, muy especialmente, de Vargas Llosa y Cortázar. En su momento, Alberto Duque López señaló además otros dos ascendientes estilísticos - Cepeda Samudio y Cabrera Infante- y describió su experiencia como lector de Collazos en los siguientes términos: Las manos del autor van moldeando las superficies y los contornos de las figuras, las amplía, las recorta, las empequeñece a su antojo y de todo ese ruido de jergas y palabras de la calle, de tecnicismos de la nueva ola y expresiones diarias, sale la prosa estupenda de sus cuentos. ${ }^{18}$

Además del entramado familiar, también aparecen otros ámbitos en estas historias. En Jueves, viernes, sábado y este sagrado respeto recorremos detalladamente la vida en un prostíbulo. Y las relaciones de pareja —con sus dinámicas de pasión, reproche o abandono- constituyen el núcleo de narraciones como Puertas abiertas, distancias cerradas, Kodac 120 y Esta mañana del mundo. En lo que respecta al modo como Collazos nos introduce en este universo para entregarnos su testimonio o su vivencia, tal vez podríamos aventurar la metáfora de una cámara invertida. Como si dijéramos: en el cine vemos siempre los escenarios, las acciones, los cuerpos; ahora bien, si queremos acceder al mundo interior de los personajes, habremos de hacerlo infiriéndolo a partir de lo que percibimos en la pantalla. En estos relatos, Collazos apela al procedimiento inverso. Nos muestra la intimidad de sus protagonistas — pensamientos, sensaciones, sentimientos-; entonces, durante el recorrido que vamos haciendo por el relato, el mundo de afuera irá ganando nitidez, paulatinamente, hasta llegar a hacerse claro. Dicha manera de narrar le otorga a estas historias tanta organicidad como poder persuasivo. Con razón el crítico Ernesto Volkening saludó tempranamente los primeros libros de Collazos, así: Su visión del mundo se distingue por la intuición de la coherencia e inseparabilidad

\footnotetext{
${ }^{17}$ García, Carlos Ernesto. "Óscar Collazos, una rueda suelta de la literatura en el carnaval de la muerte". En: Contrapunto $\mathrm{N}^{\circ}$ 45, El Salvador, enero 14 - 20 de 2008.

${ }^{18}$ Duque López, Alberto. "Los cuentos de Óscar Collazos”. En: El Heraldo, Barranquilla, enero 30 de 1968.
} 
de todas las cosas, la ausencia de barreras infranqueables, sea entre un acontecimiento y otro, sea entre la experiencia íntima del individuo y su medio. ${ }^{19}$

Hubo un momento en el cual la figura de Óscar Collazos tomó un fuerte protagonismo en la escena literaria de Latinoamérica. A finales de 1969, el gran crítico uruguayo Ángel Rama le solicitó un escrito para el semanario Marcha, de Montevideo; así fue como, atendiendo este requerimiento, el colombiano le entregó un ensayo titulado $L a$ encrucijada del lenguaje. El tema tratado era la relación entre escritura y compromiso político. Inesperadamente, dos de las grandes firmas del "Boom" — Vargas Llosa y Cortázar - respondieron al ensayo en cuestión, con lo cual se generó un gran debate de réplicas sucesivas que fueron seguidas en todo el continente. Meses más tarde se publicó en México un libro con la recopilación completa de la polémica. ${ }^{20}$ Collazos se desempeñaba entonces como director del Centro de Investigaciones Literarias adscrito a la Casa de las Américas, en Cuba, cargo en el que había reemplazado a Mario Benedetti desde enero de 1969 y en el cual permanecería hasta diciembre de 1970. Durante aquellos años trabajó en la mayor parte de las historias que integrarían su tercer libro de relatos: Biografía del desarraigo después regresó a Europa. Dichas circunstancias personales dejaron un rastro palpable en esta nueva obra. Además de las características que ya conocíamos en sus ficciones anteriores, las de ahora dejaban ver en menor o mayor

\footnotetext{
${ }^{19} \mathrm{El}$ texto del cual procede esta referencia se cierra haciendo mención a una expectativa. Y ésta consiste en si Collazos podrá expandir su talento narrativo más allá del género cuentístico; es decir, hacia la novela. Dicho texto aparece a manera de prólogo, sin fecha ni otros datos, en la edición de los cuentos que hizo la Universidad del Valle. La expectativa mencionada implica que este artículo fue escrito antes de 1975, año en que se publicó "Crónica de un tiempo muerto", la primera novela del autor.

Volkening, Ernesto. "Óscar Collazos, un cuentista de la costa del Pacífico". En: Collazos, Óscar. Primeros cuentos (1964 - 1968). Universidad del Valle. Cali, 1993. Pág. 9.

${ }^{20}$ Varios autores. Literatura y revolución y revolución en la literatura. Siglo XXI. México, 1970.

Poligramas 36, segundo semestre 2011, ISSN 0120-4130. 
medida el espíritu del compromiso. Comentemos un poco más las particularidades de esta colección.

Lo primero que llama la atención del libro en referencia es su condición miscelánea. Mezclados con los cuentos, se leen en estas páginas algunos poemas y crónicas. Curioso: los tres textos en verso integrados aquí son quizás los únicos de este género publicados por el autor: Bahía Solano — que en la primera edición aparecía sin título—, Los Snobs y Literatura e impotencia. Esto significa que la conocida disposición de Collazos para experimentar se ha hecho extensiva esta vez a la estructura misma del volumen. Por otra parte, el espectro de los escenarios en los cuales suceden estas historias también se ha ensanchado. El "Prólogo" —que es un relato y no un ensayo, como podría suponerse a juzgar por el rótulo que lo anuncia— transcurre en la Buenaventura de los libros iniciales. Se trata de un regreso al entorno familiar que ya conocíamos; pero, como a continuación nos desplazamos hacia la Bogotá de Fortuna en el sótano, el Pacífico hace las veces de punto de partida. ${ }^{21}$ Lo que sigue es un periplo del autor y sus criaturas por ciudades nuevas, como Medellín, Cartagena o París; es decir, su inserción en experiencias vitales inesperadas. La extensión de estas narraciones varía; de hecho, muchas de ellas son relatos cortos. Y en lo que respecta a los temas, las dos mayores obsesiones que atraviesan la obra de Collazos vuelven a estar en el núcleo: la marginalidad, como en Prólogo o en Biografía del desarraigo; y el erotismo, como en Ceremonias del fuego o

\footnotetext{
${ }^{21}$ A propósito de la reedición que la Universidad del Valle hizo en el año 2006 de la novela "Los días de la paciencia" (1976), Hernando Urriago escribió una reseña en la cual destacaba el papel que juega Buenaventura como origen de todo el itinerario vital y literario de Collazos: "Si es cierto que un escritor está hecho de las lecturas que dan sustento a su memoria, también es verdad que su cuerpo simbólico le debe mucho a sus vivencias, en las que pueden agolparse los amores, los triunfos y las frustraciones, los sueños y las desesperanzas, y también los viajes por el mundo o por el interior de sí mismo (...) Todas las lecturas y todos los viajes primigenios pero fundacionales de Óscar Collazos fueron emprendidos desde Buenaventura".

Urriago, Hernando. "Óscar Collazos y su primera patria literaria". En: Revista Entrelibros No 2. Programa Editorial de la Universidad del Valle. Cali, 2006. Pág. 5.
} 
en Nosotros los incurables. Sin embargo, decíamos atrás, hay en este libro un asunto que no aparecía en los anteriores: el compromiso manifiesto. Éste puede advertirse unas veces en la trama argumental y otras en la perspectiva desde la cual se cuenta.

Si bien es cierto que en alguno de los primeros cuentos de Collazos se veían ya alusiones a grandes episodios políticos de la vida nacional, esto no cobraba peso protagónico en la historia contada. Pero en la nueva colección podemos leer relatos como Noticias, en el cual se narra la manifestación de una turba enfurecida tras la muerte del sacerdote Camilo Torres, cuyo deceso se produjo en un combate con tropas del ejército. Todo ello visto desde la representación de una escena doméstica en la casa del Capitán Arturo Gutiérrez y su esposa Margarita. La situación de este militar, habilidoso jinete, no puede ser más infame: casi inmóvil, ahora cabalga sobre la silla de porcelana del retrete adonde lo ha mandado un brutal daño de estómago; entretanto, su mujer lo trata con desdén, motivada por la impericia que lastra a su marido en las lides amatorias. También los avatares de la militancia aparecen en algunos de estos relatos, como en Los vecinos nunca sospechan la verdad. Gracias al fino manejo del punto de vista, esta ficción logra transmitirnos de modo convincente el drama de un joven que vive en la clandestinidad y que es muerto a balazos por "tres hombres sin uniforme". Pero no ocurre lo propio en otros cuentos de este libro: hay veces que el compromiso del escritor ha obrado en detrimento de la narración, como sucede con Historia y colonialismo. Aquí se nos relata lo sucedido a Rosa, una mesera; tras vivir una larga y degradante prostitución, esta mujer termina suicidándose. El narrador asume una actitud de compasión hacia su protagonista y el texto adquiere tintes de denuncia, con lo cual se desdibuja su personaje para terminar convertido en un caso social. El volumen se cierra con la crónica que le da título al 
conjunto: Biografía del desarraigo. Se trata de una espléndida pieza de literatura testimonial que nos transporta a una París marginal, añorada, a una ciudad repleta de sueños rotos y realidades implacables. En este relato —acaso el mejor del libro-, Collazos nos entrega las propiedades más entrañables de su escritura: sinceridad y experiencia.

A golpes, su cuarto volumen de cuentos, también se editó en 1974. Collazos había arribado a Barcelona en 1972, justamente el año en que la escritora uruguaya Cristina Peri Rossi llegó a la ciudad en condición de exiliada. La editorial Lumen le encargó a ella dirigir la colección Palabra Menor, en la que aparecieron títulos de autores como Ana María Moix, Alejo Carpentier, Max Aub, Julio Cortázar, Felisberto Hernández y Beatriz de Maura; también numerosas traducciones. En dicha serie, precisamente, fue acogido el nuevo libro de Óscar Collazos, el cual incluía seis relatos. A propósito del hecho de que este autor colombiano haya publicado dos libros el mismo año —en dos de las editoriales más importantes de la lengua española: Siglo XXI, Buenos Aires y Lumen, Barcelona—, valdría la pena mencionar una circunstancia que ha sido muy discutida y bastante polémica. Me refiero al efecto eclipse que operaron los escritores del "Boom" sobre la generación siguiente en lo que toca al vínculo con editores y lectores. En el caso de Colombia, además de Collazos, la cohorte en cuestión incluiría a Germán Espinosa, R. H. Moreno-Durán, Fernando Cruz Kronfly, Fanny Buitrago, Ricardo Cano Gaviria, Marvel Moreno, Luís Fayad, entre otros narradores de notable calidad literaria. ${ }^{22}$ En efecto,

\footnotetext{
${ }^{22}$ El escritor y crítico Eduardo García Aguilar, quien realizó una excelente antología de relatos escritos por estos autores, afirmaba en el prólogo: “Catalizador desde diferentes estilos y temas de esa modernidad subyacente desde los años cincuenta, el vendaval del Boom narrativo latinoamericano centró de repente la mirada en los grandes mandarines del movimiento durante tres décadas y dejó a esta nueva generación de narradores en una especie de purgatorio del que aún no salen".

García Aguilar, Eduardo (selección, prólogo y notas). Veinte ante el milenio: cuento colombiano del siglo XX.

Universidad Nacional Autónoma de México. México, 1994. Pág. 10.
} 
resulta innegable que se presentó en los años 60 y 70 un despliegue editorial y publicitario sin precedentes en nuestra lengua. Y su epicentro fue la ciudad de Barcelona y el llamado "Boom" latinoamericano; sin embargo, no es del todo cierto que los escritores de la generación posterior hayan sido invisibilizados por completo, pues, en mayor o menor medida, sus obras han sido publicadas en editoriales de prestigio y han conseguido forjar sus propios nichos de lectores.

Pero volvamos a los relatos integrados en A golpes. En éstos encontramos a un escritor mucho más maduro; es decir, con un dominio pleno del arte narrativo. Porque sorprende la tremenda precisión en el manejo que Collazos despliega aquí de técnicas muy complejas, sobre todo el punto de vista. Una buena ilustración podemos hallarla en el texto titulado Testigo presencial, donde se aborda la historia de Martín Llanos, personaje que ha presenciado un crimen callejero cuya víctima es un joven muchacho. El hombre se debate moralmente entre la culpa que le genera su silencio y el coraje que requeriría para llevar a cabo el acto de denuncia - las características de los responsables apuntan, en ese contexto de violentas represiones, a un crimen de Estado- La narración nos transporta a través del dilema ético y el testimonio ilusorio de Llanos frente a las autoridades. Aparece, entonces, un tema que ya había esbozado Collazos en relatos anteriores; pero que, en este libro, toma una mayor resonancia: la verdad. No como entidad unívoca y constatable sino como aquella versión de los hechos que termina imponiéndose socialmente; de allí que el modo como se cuentan resulte crucial. Esto se lo repite a sí mismo Martín Llanos, como nos lo repite el narrador de Circulación de la verdad al abordar el caso de Margarita Sánchez Gutiérrez, una mujer que ha aparecido muerta en el cuarto de su pensión. Diríamos: Collazos regresa así sobre un asunto que ya lo había 
interesado antes, aunque esta vez lo hace con mayor énfasis. Por otra parte, hay un elemento novedoso en este volumen, un rasgo narrativo que no conocíamos en los tres anteriores. Me refiero a lo que sucede con el tono del cuento final: Cortejando al Este. Estamos ante una parodia sobre la política y el arte de la seducción. João, un brasilero asentado transitoriamente en La Habana, pretende a dos mujeres: Eva, de Bratislava y Marina, de Praga. La narración está impregnada de un fuerte aire humorístico, algo que se incrementará con la llegada de la rusa Elena, joven bella y desinhibida. No, no habíamos percibido antes en el Collazos cuentista este registro de naturaleza cómica.

\section{3}

La fecha llama la atención, y mucho: 2000. Este fue el año en que se publicó la quinta colección: Adiós Europa, adiós. ¿Quiere decir que durante más de veinticinco años dejó de escribir cuentos Óscar Collazos? No exactamente. Si bien centró su atención especialmente en otros terrenos — la novela, el ensayo, el periodismo-, hay un hecho significativo, en relación con este género, que podríamos rememorar. En 1982, Collazos ganó el Premio de Cuentos Ciudad de León, en España, con un libro titulado De un amor a otro mar. Al parecer, la edición que realizó el Ayuntamiento fue muy deficiente y este volumen nunca llegó a las librerías. El autor no lo menciona cuando se refiere a su propia bibliografía. Resulta bastante probable que algunos relatos integrados en la colección que se publicó en el 2000 hayan sido reelaboraciones provenientes de aquel libro. Otros habrían sido escritos posteriormente, como por ejemplo Alguien llama a mi puerta, en el que se advierten aspectos de una Cartagena más reciente y, sobre todo, referencias culturales nuevas — recordemos que Óscar Collazos regresó a Colombia y que, a partir de 
1989, se radicó definitivamente en la ciudad heroica—. Adiós Europa, adiós no sólo incluye cuentos compuestos aquí y allá sino que recrea contextos europeos y colombianos. Cuando Marcos Fabián Herrera le preguntó por las peculiaridades de esta obra, Collazos respondió:

En este libro de cuentos hay dos topografías culturales: la provinciana de mis orígenes, incluso el escenario de la Bogotá actual (en el último cuento) y el desarraigo de aquellos personajes que viven en Europa. No hay desarraigo sin la evocación obsesiva de las raíces, que es lo que hace el pintor Ernesto [en el relato que da título al volumen], muriéndose en París. ${ }^{23}$

Sin embargo, la variedad de entornos y las obsesiones temáticas del autor son quizás las únicas trazas que este nuevo libro comparte con los anteriores. Me explico: la formalidad narrativa y la textura de la prosa han cambiado ostensiblemente. Mencionemos algunas de estas transformaciones, y empecemos señalando que Óscar Collazos ha sido siempre un escritor fuertemente vinculado con la tradición literaria, un gran lector. El diálogo que ha sostenido con ésta se expresa no sólo en sus diversas influencias sino también a través de recursos alusivos, como aquellos epígrafes que suelen anteceder los relatos de sus tres primeros libros. En ellos podemos leer citas de Saul Bellow, Enrique Lihn, Álvaro Mutis, Karl Marx, Cesare Pavese, Allen Ginsberg, Saint-Exupéry, Aimé Cesaire, Thomas Mann, Carlos Monsiváis, Juan Carlos Onetti, o Louis-Ferdinand Céline. Pues bien, en este quinto libro ha cambiado el lugar del diálogo en cuestión. Tenemos que algunos de sus personajes son lectores en ejercicio, de manera que en el interior de la narración aparecen observaciones puntuales a diversos autores y obras. Y más aún: leemos en éstas verdaderas pinceladas de crítica literaria que pasan por el homenaje, el sumario, la anticipación, el análisis, o la detracción. Así, por ejemplo, en Adiós Europa, adiós se nos

\footnotetext{
${ }^{23}$ Herrera, Marcos Fabián. "Ni héroe ni villano: simplemente un escritor con conciencia de época. Entrevista con Óscar Collazos”. En: Revista Espéculo N 33. Universidad Complutense de Madrid. Madrid, julio - octubre de 2006. 
habla de Faulkner y su Luz de agosto, de Maupassant y su Bel ami, de Neruda y su Tango del viudo, entre otros. O en Soledad al final del coche cama, de la fuerza que tiene la intriga en Extraños en un tren, de Patricia Highsmith. O en Invitada del tiempo, de la famosa revista Selecciones y de Vargas Vila. O en Alguien llama a mi puerta, del Pereira de Tabucchi y el Gaviero de Mutis. Todas estas anotaciones se implican simbólicamente con la trama que se nos está contando cada vez: estamos frente a relatos de una admirable factura literaria. Ahora bien, entre las ocho narraciones que componen esta colección, hay por lo menos dos que considero magistrales, absolutamente memorables. Una es Soledad al final del coche cama, en la cual se nos cuenta la historia del señor Hernández y su esposa, quienes viajan por primera vez de Madrid a Barcelona, en un moderno tren. Se trata de una alegoría entrañable sobre la soledad y la culpa. La otra, Mariposa sin alas, sucede en Bogotá y nos habla de Nicolás Herrera Ríos, un bellísimo travesti que ha llegado a la capital buscando realizar sus sueños. Aquí se dan cita la crueldad y la desilusión.

Pero decíamos atrás que es en la narración y en la prosa donde más se notan los cambios. La escritura de Collazos en este nuevo volumen ha dejado atrás el experimentalismo que caracterizaba los anteriores. Éste se correspondía con aquel registro estético que estaba en boga durante los años 60 y 70 -heredero de las dinámicas propiciadas por las vanguardias artísticas durante la primera mitad del siglo XX-. Ahora, en estos cuentos más recientes, encontramos que la sencillez de las frases favorece una sintonía expedita con el lector de hoy. El uso de una puntuación más ortodoxa, así como las fórmulas tradicionales para referir los parlamentos de los personajes, nos ponen sobre la pista de un autor que busca claridad y comunicabilidad, dos valores literarios sumamente 
apetecidos en la narrativa actual. Ya en lo que toca a las influencias que se advierten en esta última etapa de su obra, quisiera destacar dos fuentes generales. Por una parte, la novelística contemporánea de suspenso — como las narraciones de los ya mencionados Tabucchi y Highsmith—; por otra, el cuento clásico del siglo XIX. La primera se nota en el esmero con que han sido dispuestos los entramados; es decir, el modo como se encadenan las acciones en función de que el lector vaya hasta el final de cada historia buscando despejar alguna incógnita concreta $\longrightarrow$, para referir un caso puntual, en la forma como está narrado el relato Mariposa sin alas, la cual nos recuerda aquellas anáforas del lenguaje oral utilizadas por Tabucchi en Sostiene Pereira—. La segunda influencia podríamos ilustrarla indicando los ecos que se perciben de un relato como $\mathrm{La}$ obra maestra desconocida, de Balzac, en el cuento titulado Adiós Europa, adiós; o las resonancias de aquellas apariciones misteriosas que tanto apasionaban a Poe y Maupassant, en Alguien llama a mi puerta.

Bien sea metido en los avatares de la experimentación, o sorteando las particularidades del compromiso político, o lidiando con los requerimientos que en la actualidad plantea la cultura de masas, Óscar Collazos nos entrega siempre la experiencia de un escritor que ha estado atento al pulso de su tiempo. Sus cuentos son el testimonio y la vivencia de un viajero infatigable que ha trasegado geografías diversas, que ha empleado a fondo su pluma desde una sinceridad a veces descarnada pero siempre reveladora. La suya es sin duda una de las obras narrativas más sólidas de la literatura colombiana contemporánea. Y recorrerla es una gran fortuna para cualquier lector.

Madrid, febrero 19 de 2010.

Poligramas 36, segundo semestre 2011, ISSN 0120-4130. 